\title{
Association between uterine disease and indicators of neutrophil and systemic energy status in lactating Holstein cows
}

\author{
K. N. Galvão, ${ }^{*}$ M. J. B. F. Flaminio, ${ }^{*}$ S. B. Brittin, ${ }^{*}$ R. Sper, ${ }^{*}$ M. Fraga, ${ }^{*}$ L. Caixeta,† A. Ricci,ł C. L. Guard, $†$ \\ W. R. Butler, $\S$ and R. O. Gilbert*1 \\ *Department of Clinical Sciences, and \\ †Department of Population Medicine and Diagnostic Sciences, Cornell University, Ithaca, NY 14853 \\ $\ddagger$ Facultà di Medicina Veterinaria, Università di Torino, Torino, Italia \\ §Department of Animal Science, Cornell University, Ithaca, NY 14853
}

\section{ABSTRACT}

The objective of this study was to evaluate the association between uterine disease and indicators of neutrophil (PMN) and systemic energy status in dairy cows. Peripheral blood $(120 \mathrm{~mL})$ was collected weekly from 84 Holstein cows for PMN isolation and plasma collection from calving until $42 \mathrm{~d}$ in milk (DIM). The final analysis included 80 cows. Of those, 20 cows were classified as having metritis (fetid uterine discharge and fever), 15 as having subclinical endometritis (SCE; $\geq 10 \%$ PMN on uterine cytology), and 45 as healthy controls. Plasma haptoglobin concentration was increased only in cows that developed metritis. Neutrophil glycogen content was reduced in cows developing metritis compared with healthy cows on the day of calving and at 7 and 42 DIM. Cows with SCE had lower PMN glycogen content than healthy cows at 7,28 , and 42 DIM. Blood glucose was affected by disease status within parity. Primiparous metritis cows had greater blood glucose concentrations than healthy primiparous cows. Multiparous metritis cows tended to have lower blood glucose concentration than multiparous SCE cows. Cows that developed metritis and SCE had or tended to have greater NEFA and BHBA than healthy cows, mainly around calving. At calving, cows that developed metritis had higher plasma estradiol concentration than healthy cows and greater plasma cortisol than cows that had SCE. Plasma insulin was not affected. Plasma glucagon was increased for SCE cows. Cows that developed uterine disease experienced a greater degree of negative energy balance and had decreased lower intracellular PMN glycogen levels, which could be a major predisposing factor for disease because of decreased availability of oxidative fuels.

Key words: metritis, glycogen, energy balance, dairy cow

Received July 7, 2009.

Accepted January 2, 2010.

${ }^{1}$ Corresponding author: rob.gilbert@cornell.edu

\section{INTRODUCTION}

During transition to lactation, dairy cows undergo a period of negative energy balance in which the energy consumed does not meet the energy demands for growth, maintenance, and milk production (Butler et al., 1981; Doepel et al., 2002). This period is characterized by a decrease in DMI, leading to a sharp decrease in glucose and an increase in body fat mobilization in the form of NEFA and resulting in accumulation of products of incomplete oxidation of NEFA such as BHBA (Vazquez-Añon et al., 1994).

Neutrophils (polymorphonuclear neutrophils, PMN) are the main leukocyte type involved in bacterial clearance after uterine infection (Hussain, 1989; Gilbert et al., 2007). However, during the period of negative energy balance, dairy cows experience a reduction in PMN function, including reduced killing capacity (Kehrli and Goff, 1989; Gilbert et al., 1993; Cai et al., 1994). In fact, multiparous cows that develop uterine disease have more pronounced decreases in DMI, increases in NEFA and BHBA, and decreases in blood PMN killing ability (Hammon et al., 2006) and phagocytosis (Kim et al., 2005).

Whereas plasma NEFA (Hammon et al., 2006) and BHBA (Suriyasathaporn et al., 2000) are associated with PMN function, PMN depend mainly on glucose uptake and glycolysis for the energy required for chemotaxis, but almost exclusively on glycogen stores for phagocytosis and microbial killing even in the presence of extracellular glucose (Kuehl and Egan, 1980; Borregaard and Herlin, 1982; Weisdorf et al., 1982a,b). Therefore, it is possible that the low glucose levels observed during the transition to lactation (Vazquez-Añon et al., 1994) could directly impair PMN chemotaxis and could lead to decreased PMN glycogen stores, thereby impairing phagocytic and killing capability and predisposing affected cows to disease.

Glycogen storage disease in humans, a condition characterized by the inability of cells including leukocytes to process intracellular glucose (Kim et al., 2006), leads 
to defects in neutrophil respiratory burst, chemotaxis, and calcium influx in response to bacterial stimulation. Moreover, in an experimental model of peritoneal inflammation, macrophage production of chemokines and peritoneal PMN accumulation were decreased in mice with glycogen storage disease (Kim et al., 2006).

Therefore, we hypothesized that lactating dairy cows that develop uterine disease would have lower glucose, or decreased PMN glycogen stores, or both, in early lactation compared with healthy cows. The objective was to compare plasma glucose, intracellular PMN glycogen concentration, and indicators of energy balance (NEFA and BHBA) in cows that develop uterine disease and healthy cows in the first 42 DIM. Because glucose can be increased on the day of calving in response to cortisol, and glucose homeostasis is controlled mainly by insulin and glucagon, those hormones were also evaluated. Because estradiol is believed to affect PMN function negatively, this hormone was also evaluated. Because milk production can deplete blood glucose in early lactation, milk yield was evaluated.

\section{MATERIALS AND METHODS}

\section{Animals, Housing, and Feeding}

Eighty-four cows (38 primiparous and 46 multiparous) from a commercial Holstein dairy farm located in Cayuga County, New York, were enrolled in the study at calving, from April to November of 2007. A physical exam was performed at calving and only cows appearing healthy were enrolled. Cows that had uterine prolapse or cesarean section or were severely lame were not enrolled. The herd had 3,000 milking cows and the rolling herd average was about 12,000 kg of milk. Primiparous and multiparous cows were housed separately in freestall facilities. Cows were moved to far-off pens $60 \mathrm{~d}$ before expected calving date and moved to closeup pens $21 \mathrm{~d}$ before expected calving date. Cows were moved to calving pens that would hold up to 5 cows 3 $\mathrm{d}$ before expected calving or when imminent signs of calving such as exposure of fetal membranes appeared. After calving, cows were milked and then transferred to fresh-cow pens, where they stayed for about $30 \mathrm{~d}$, and were subsequently moved to a mid-lactation pen for the remainder of the experiment. Lactating cows were milked 3 times daily and were fed the same TMR formulated to meet or exceed the NRC (2001) nutrient requirements for lactating Holstein cows weighing 680 $\mathrm{kg}$ and producing $45 \mathrm{~kg}$ of $3.5 \% \mathrm{FCM}$ twice daily.

\section{Sample Collection}

All cows had $120 \mathrm{~mL}$ of blood collected weekly from the jugular vein, using two 60 -mL syringes with $3 \mathrm{~mL}$ of $0.5 M$ EDTA each and a 12-gauge needle, from the day of calving until 42 DIM. For blood collection, cows had their head locked into headlock stanchions and tied to one side using a halter; the hair over the jugular vein was clipped and the skin was disinfected using iodine solution. The side of blood collection was alternated each week to prevent phlebitis. Blood was collected immediately after the morning milking. At the time of blood collection, body condition was scored using a 5 -point ( $1=$ thin to $5=$ fat) system (Ferguson et al., 1994).

\section{Glycogen, Glucose, Hormones, and Other Metabolites}

After blood collection, syringes were gently inverted 10 times to allow thorough mixing with EDTA, blood glucose was measured using a portable glucometer (AccuCheck Active, Roche Diagnostics, Indianapolis, IN), and the syringes were placed on ice and transported to the laboratory within $4 \mathrm{~h}$. To validate the use of the glucometer for dairy cows, we compared the results from the glucometer with those of a biochemistry analyzer (BioAnalyzer model 7100, YSI-Life Sciences, Yellow Springs, OH) using EDTA plasma samples from 51 lactating cows from the Cornell University dairy herd. Figure 1a shows a Passing-Bablok correlation plot between concentrations measured by the BioAnalyzer and the glucometer. According to the Cusum test, there was no significant deviation from linearity $(P>0.1)$, indicating that a linear model fits the data. Pearson correlation coefficient was $0.82(P<0.001)$. Regression analysis of the data yielded the following equations ( $95 \%$ CI are shown in parentheses): glucometer glucose $=-0.96(-2.10$ to -0.04$)+1.43(1.14$ to 1.77$) \times$ Bioanalyzer glucose. The intercept $95 \%$ confidence interval did not include 0 , indicating that both methods differ at least by a constant amount (bias), and the slope 95\% confidence interval did not include 1, indicating the presence of a proportional bias. Figure $1 \mathrm{~b}$ shows a Bland-Altman plot of the plasma glucose measured with the BioAnalyzer and the blood glucose measured with the glucometer (Bland and Altman, 1986). The concentrations measured using the glucometer were on average 0.53 points higher than the BioAnalyzer [3.99 (range: 3.0-5.1) vs. 3.46 (range: 2.78-4.05) mmol/L]. The differences in glucose measurements between the 2 methods are scattered evenly, which indicates an absolute systematic error, and most of the points fall around the mean difference $(0.53 \mathrm{mmol} / \mathrm{L})$, which indicates good agreement. Only 2 points $(3.8 \%)$ lie outside the $95 \%$ confidence limits. The generally higher results obtained with the Glucometer probably reflect glucose metabolism in the time between sampling and BioAnalyzer testing. 

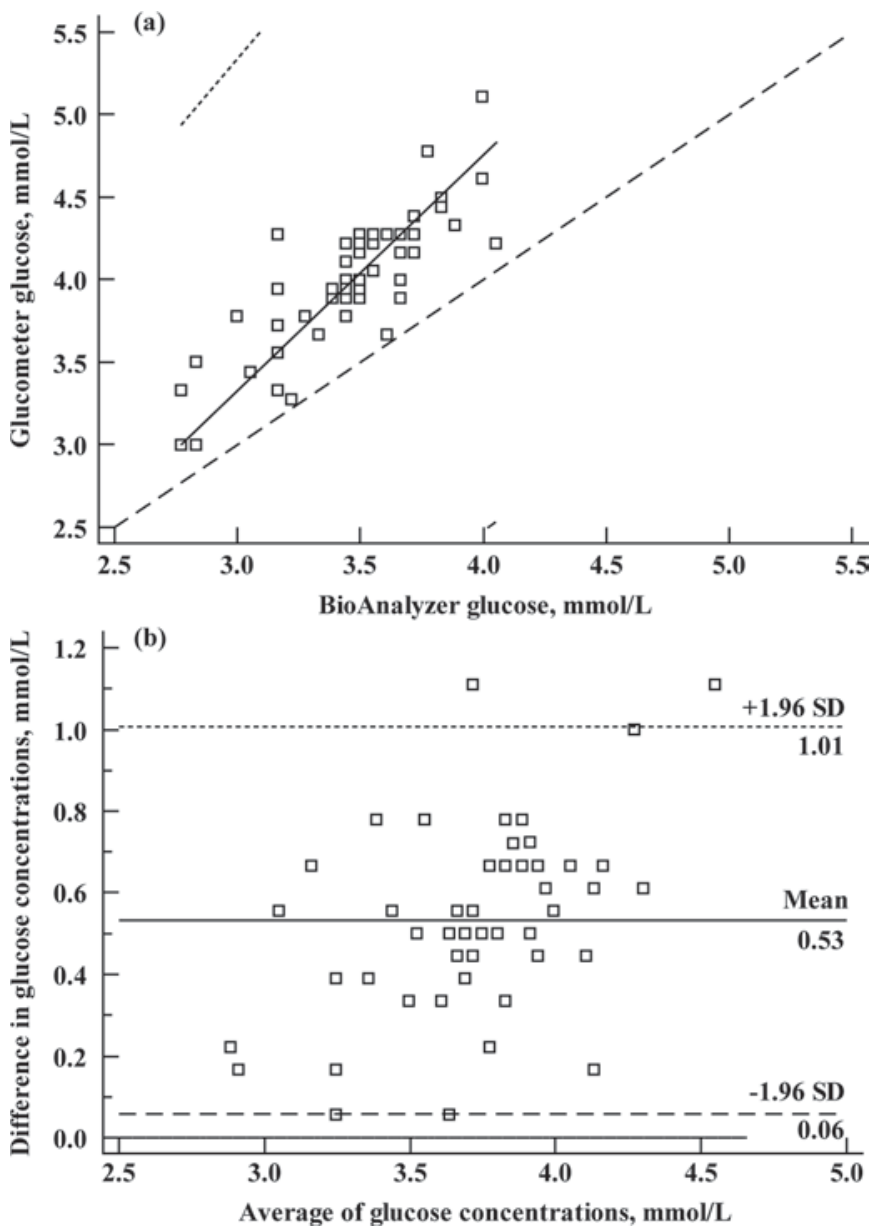

Figure 1. a) Passing-Bablok correlations for glucometer (AccuCheck Active, Roche Diagnostics, Indianapolis, IN) glucose and Bioanalyzer (BioAnalyzer model 7100, YSI-Life Sciences, Yellow Springs, OH) glucose concentrations. Scatter diagram with the regression line (solid line), the confidence interval for the regression line (dotted lines), and identity line ( $\mathrm{x}=\mathrm{y}$; dashed line). b) Bland-Altman plot showing the average of glucose concentration measured by the portable glucometer and by the BioAnalyzer ( $\mathrm{x}$-axis) plotted against the difference in glucose concentration measured by the portable glucometer and by the BioAnalyzer (y-axis). Relative differences between glucometer glucose and Bioanalyzer glucose concentrations are plotted against the mean concentrations determined by both methods. The mean differences are shown by a solid line, and the $95 \%$ limits of agreement are displayed by dotted lines.

In the laboratory, $40 \mathrm{~mL}$ of blood were transferred into three $50-\mathrm{mL}$ polypropylene centrifuge tubes (Corning Life Sciences, Lowell, MA) and centrifuged at $1,200 \times g$ for $30 \mathrm{~min}$ to separate the plasma; $10 \mathrm{~mL}$ of plasma was harvested and frozen at $-20^{\circ} \mathrm{C}$ for hormone and metabolite assays. Blood PMN were isolated as described previously (Roth and Kaeberle, 1981). After isolation, $10^{7} \mathrm{PMN}$ were frozen in duplicate for later glycogen determination using a micromodification of the method of Keppler and Decker (1974) as described previously (Weisdorf et al., 1982a). Briefly, glycogen was hydrolyzed to glucose using amyloglucosidase; available glucose was determined by reacting $50 \mu \mathrm{L}$ of supernatant with a $1-\mathrm{mL}$ mixture of $1 \mathrm{~m} M$ ATP, 0.9 $\mathrm{m} M$ NADP, $5 \mu \mathrm{g}$ of glucose-6-phosphate dehydrogenase (G6DP), $0.3 M$ triethanolamine, and $4 \mathrm{mM} \mathrm{MgSO}$ and recording the appearance of NADPH after the addition of $5 \mu \mathrm{L}$ of hexokinase $(2 \mathrm{mg} / \mathrm{mL})$ as change in optical density at $340 \mathrm{~nm}$ on a spectrophotometer. This change in optical density was compared with a standard curve of glycogen assayed in similar fashion, and results were expressed as micrograms of glycogen $/ 10^{6} \mathrm{PMN}$.

Plasma concentrations of NEFA were analyzed by enzymatic analysis (NEFA-C kit, Wako Pure Chemical Industries, Osaka, Japan) using modifications described by McCutcheon and Bauman (1986) and Sechen et al. (1990). Plasma concentrations of BHBA were quantified (BHBA dehydrogenase) using a commercial kit (kit 310-UV, Sigma Chemical). All spectrophotometric measurements were conducted using a microplate reader (BioTek Instruments, model EL 340, Winooski, VT). In addition, plasma was analyzed for concentrations of estradiol and cortisol by RIA using the Coat-A-Count estradiol and cortisol assay kits (Siemens Medical Solutions Diagnostics, Los Angeles, CA), respectively. Plasma concentrations of insulin we determined by RIA (Ehrhardt et al., 2001) using bovine insulin (Elanco Animal Health, Greenfield, IN) and glucagon (Linco RIA kit, Linco Research, St. Charles, MO) kits. Intraand interassay coefficients of variation were 1.8 and $2.6 \%, 5.1$ and $6.7 \%, 6.1$ and $9.6 \%, 3.0$ and $9.8 \%, 5.6$ and $7.2 \%$, and 6.5 and $8.1 \%$, for NEFA, BHBA, estradiol, cortisol, insulin, and glucagon, respectively.

\section{Evaluation of Uterine and Metabolic Diseases}

Cows were evaluated daily for signs of metritis in the first 14 DIM. All uterine evaluations and samplings were performed by a single investigator (the first author). Metritis was characterized by the presence of watery, fetid vaginal discharge and rectal temperature $\geq 39.5^{\circ} \mathrm{C}$. Cows having fetid vaginal discharge but no fever were not excluded from the study. Five cows had fetid vaginal discharge but no fever; 3 were later diagnosed with subclinical endometritis (SCE) and 2 remained as controls. Cows with clinical metritis received 2 boluses of aspirin (15.6 g of acetylsalicyclic acid/bolus; AgriLabs, St. Joseph, MO) until the fever improved or for a maximum of $3 \mathrm{~d}$ and ceftiofur hydrochloride for 5 consecutive days at a dose of $2.2 \mathrm{mg} / \mathrm{kg}$ of BW (Excenel RTU EZ, ceftiofur hydrochloride sterile suspension, Pfizer Animal Health, New York, NY). Febrile or lethargic cows were checked for acetonuria (acetoacetic acid) as an indicator of ketosis using ketone strips (Ketostix, Bayer Health Care, Tarrytown, NY). Cows with moder- 
ate or high ketones were treated with $500 \mathrm{~mL}$ of $50 \%$ dextrose intravenously (AgriLabs) until urine ketones were lowered. Blood sampling was performed before treatment administration. At 42 DIM, a low-volume uterine lavage was performed on all cows for diagnosis of subclinical endometritis based on the proportion of PMN out of a total of 200 cells, including all leukocyte types and epithelial cells but excluding erythrocytes, as described previously (Gilbert et al., 2005). Based on a larger experiment (Cheong et al., 2008) and consistent with current recommendations (Sheldon et al., 2006) the proportion of PMN that classified cows as having subclinical endometritis was $\geq 10 \%$.

\section{Statistical Analyses}

This was an observational cohort study. Two out of the 38 primiparous and 2 out of the 46 multiparous cows enrolled in the study were culled before the end of the observation period and excluded from the analysis. One of the primiparous cows was culled because of low milk yield after surgical correction of left-displaced abomasum and the other because of herpesviral teat lesions. The multiparous cows were culled because of severe lameness. Two cows that had retention of fetal membranes ( 1 primiparous and 1 multiparous) were not excluded. Therefore, 80 cows (36 primiparous and 44 multiparous) were used for the final analysis of the association between uterine disease and the outcomes of interest. The cows were classified into 3 categories: 1) cows that developed metritis in the first 14 DIM; 2) cows that did not develop metritis and were diagnosed with subclinical endometritis at 42 DIM; and 3) healthy control cows. Continuous outcomes such as PMN glycogen concentration, hormones, and metabolites were analyzed by ANOVA for repeated measures using the MIXED procedure of SAS (version 9.1; SAS Inst. Inc., Cary, NC). Each outcome was analyzed in separate models over the whole experimental period. Models included the effects of uterine disease, parity (primiparous vs. multiparous), mean BCS ( $<2.75$ vs. $\geq 2.75$ ), time (day of blood collection: $0,7,14,21,28$, 35 , and 42), and interactions between uterine disease and other covariates. Uterine disease and parity were forced into the models, but other covariates were manually removed if $P>0.15$. Because data were collected longitudinally, data points were correlated within each cow; therefore, cow was included in the analysis as a random effect. Because all the outcomes evaluated were biological samples collected at regular intervals, a first-order autoregressive covariance structure was used. When either an effect of metritis or subclinical endometritis or an interaction between metritis or subclinical endometritis and time was observed, post-hoc multiple comparisons were performed using the Bonferroni adjustments in SAS.

Evaluation of normality of the residuals was performed in Minitab (version 15, Minitab Inc., State College, PA) by inspection of standardized residuals plotted against predicted values for the residuals using the regression option in Minitab. Residuals fit to a normal distribution were also evaluated. Standardized residuals for glycogen, glucose, and glucagon were found to be normally distributed; however, raw data for haptoglobin, NEFA, BHBA, cortisol, and insulin were transformed to their base-10 logarithm to achieve normality. After statistical analysis, transformed data were back-transformed to report least squares means. Normality was not achieved for estradiol data; therefore, it was analyzed nonparametrically using the Kruskal-Wallis test in Minitab. Proportions were compared by chi-square analysis using Minitab. Evaluation of agreement between glucose measurements obtained with the BioAnalyzer and the glucometer, including construction of Passing-Bablok and Bland-Altman plots, were performed using MedCalc (version 9.2, MedCalc Software, Mariakerke, Belgium). Differences with $P \leq 0.05$ were considered significant and $0.05<P \leq 0.10$ were considered a tendency. Interactions were considered to be significant when $P \leq 0.15$.

\section{RESULTS}

Of the 80 cows used in the final analysis, 20 were diagnosed with metritis and classified as metritis for the statistical analysis; 23 were diagnosed with SCE but only 15 were classified as SCE for the statistical analysis because 8 of them had metritis and therefore were classified as metritis; and 45 were not diagnosed with metritis or SCE and were classified as healthy controls. Although 8 out of 20 cows diagnosed with metritis were also diagnosed with SCE, cows that had metritis were not more likely to be diagnosed with SCE than cows that did not have metritis $[40 \%(8 / 20)$ vs. $25 \%(15 / 60)$; $P=0.20]$. However, in a larger experiment $(779$ cows evaluated), the difference observed here was confirmed and cows that had metritis were more likely to have SCE than cows that did not have metritis [39\% (29/75) vs. $23 \%(164 / 704) ; P=0.003$; Cheong et al., 2008]. Incidence of metritis was similar between multiparous and primiparous cows $[23 \%(10 / 44)$ vs. $28 \%(10 / 36)$; $P=0.60]$, but prevalence of SCE tended to be greater in multiparous cows compared with primiparous cows [36\% (16/44) vs. $19 \%(7 / 36) ; P=0.09]$. Mean and median day of diagnosis of metritis was 7 DIM (range: 3-12 DIM). Cows that had metritis were more likely to be diagnosed with clinical ketosis based on ketone strips compared with healthy cows $[35 \%(7 / 20)$ vs. $2 \%$ 


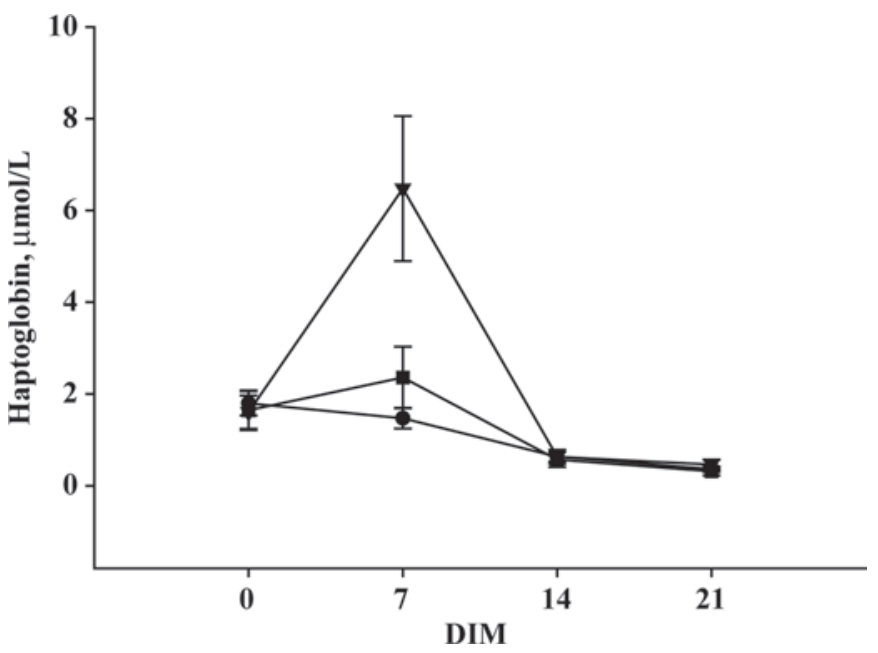

Figure 2. Least squares means \pm SEM for plasma haptoglobin concentrations for cows that developed metritis up to 14 DIM ( $\boldsymbol{\nabla}$ ), had subclinical endometritis at 42 DIM (ם), or remained healthy up to $42 \operatorname{DIM}(\bullet)$.

$(1 / 45) ; P<0.01$; Fisher's exact test] and tended to be more likely than cows that had SCE $[35 \%(7 / 20)$ vs. $7 \%$ $(1 / 15) ; P=0.10]$. Mean and median day of diagnosis of ketosis was 6 DIM (range: 2-10 DIM).

Figure 2 shows the plasma haptoglobin concentrations from calving until 21 DIM according to disease status. There was an interaction between uterine disease and time $(P<0.001)$ in which metritis cows had greater plasma haptoglobin concentration than SCE cows $(P=$ $0.005)$ or healthy cows $(P<0.001)$ at 7 DIM. The SCE cows had a slight increase in haptoglobin concentration at 7 DIM, but concentration was not different from healthy cows $(P=0.13)$. There was also a main effect of time $(P<0.001)$; plasma haptoglobin concentrations peaked at 7 DIM and then decreased sharply until 21 DIM. No other variable affected plasma haptoglobin concentrations.

Figure $3 \mathrm{a}$ shows the plasma NEFA concentrations from calving until 42 DIM according to disease status. There was an interaction between uterine disease and time $(P=0.11)$ in which metritis cows tended to have greater NEFA concentrations at calving $(P=0.08)$ and at $35 \mathrm{DIM}(P=0.06)$ than healthy cows, whereas SCE cows had greater $(P<0.05)$ plasma NEFA concentrations at calving and at 35 DIM than healthy cows. There were also main effects of parity $(P=0.02)$ and time $(P$ $<0.001$ ) on plasma NEFA concentrations. Primiparous cows had greater NEFA concentration compared with multiparous cows (mean \pm SEM: $302.1 \pm 21.1$ vs. 240.5 $\pm 14.6 \mu \mathrm{Eq} / \mathrm{L}$ ). Plasma NEFA concentrations were greatest at calving and at 7 DIM and then decreased steadily from 7 DIM until 42 DIM. No other variable affected plasma NEFA concentrations.
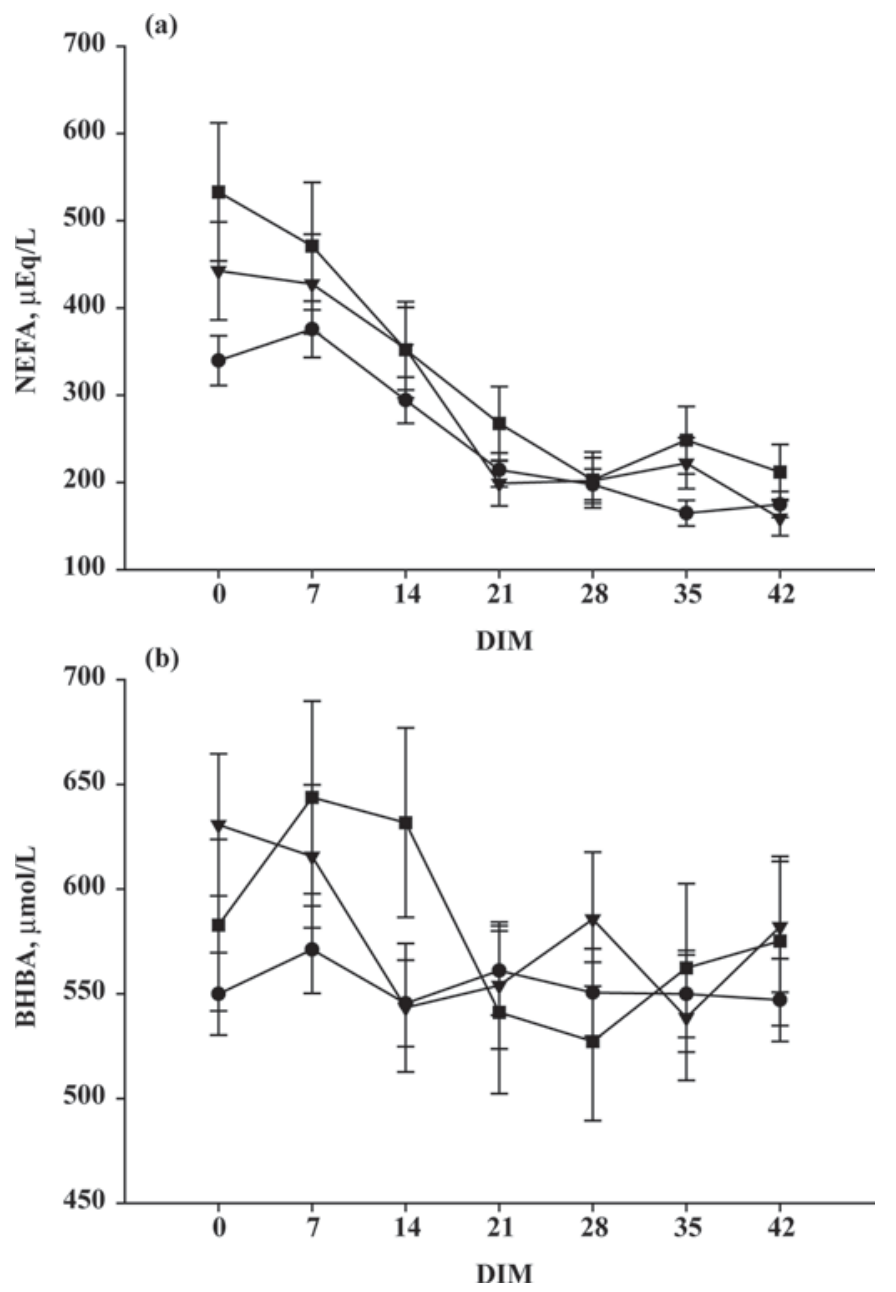

Figure 3. Least squares means \pm SEM for a) plasma NEFA and b) BHBA concentrations for cows that developed metritis up to 14 DIM $(\boldsymbol{\nabla})$, had subclinical endometritis at 42 DIM ( $)$, or remained healthy up to 42 DIM $(\bullet)$.

Figure 3b shows plasma BHBA concentrations from calving until 42 DIM according to disease status. There was an interaction between uterine disease and time $(P$ $=0.12)$ in which metritis cows had greater $(P=0.03)$ BHBA concentrations on the day of calving compared with healthy cows, whereas SCE cows tended to have greater BHBA concentrations at $7(P=0.10)$ and 14 $(P=0.07)$ DIM compared with healthy cows. There was an effect of time $(P=0.05)$ in which plasma BHBA concentrations peaked at 7 DIM, then decreased from 7 DIM to 14 DIM, and remained constant until 42 DIM. No other variable affected plasma BHBA concentrations.

Figure 4 shows the blood PMN glycogen concentrations from calving until 42 DIM according to disease status. There was an interaction $(P=0.001)$ between uterine disease and time. Metritis cows had lesser $(P=$ 


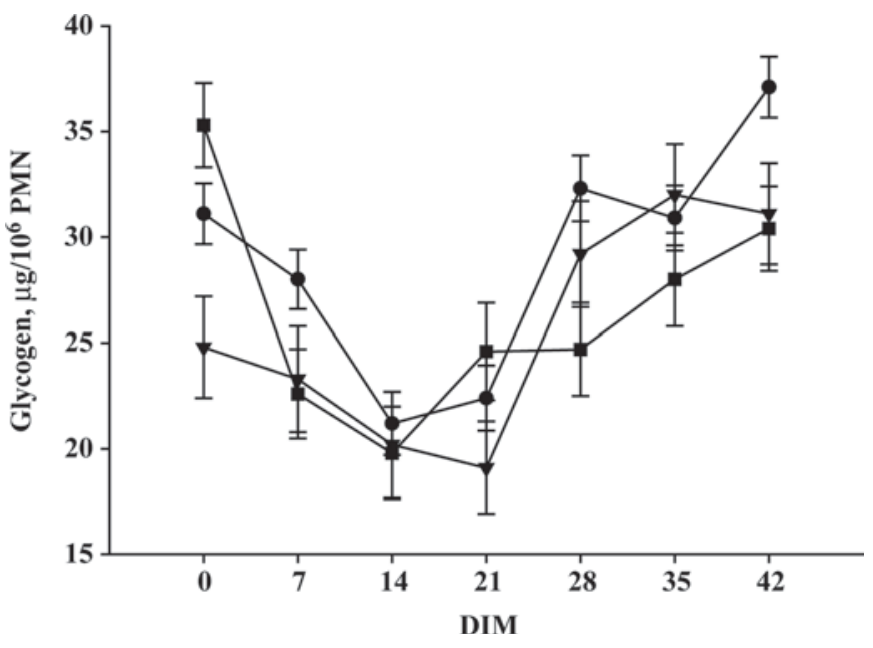

Figure 4. Least squares means \pm SEM for blood neutrophil (PMN) glycogen concentrations for cows that developed metritis up to 14 DIM ( $)$, had subclinical endometritis at 42 DIM ( $)$, or remained healthy up to 42 DIM $(\bullet)$.

0.001) blood PMN glycogen concentration than SCE cows at calving and lesser than healthy cows at calving $(P=0.03)$ and at $7(P=0.10)$ and 42 DIM $(P=$ $0.05)$. The SCE cows had lesser blood PMN glycogen than healthy cows at $7(P=0.06), 28(P=0.01)$, and 42 DIM $(P=0.02)$. There was also an effect of time $(P<0.001)$, and blood PMN glycogen concentrations decreased from calving until 14 DIM, then recovered to a level equivalent to that at calving by 42 DIM. No other variable affected PMN glycogen concentrations.

Figure 5 shows the blood glucose concentrations for primiparous (Figure 5a) and multiparous (Figure 5b) cows from calving until 42 DIM according to disease status. There was a 3 -way interaction among uterine disease, parity, and time $(P=0.07)$ on blood glucose concentrations. Primiparous metritis cows had greater $(P \leq 0.05)$ glucose concentrations than primiparous SCE cows or healthy primiparous cows on the day of calving and at 14 DIM, and greater than SCE cows at 42 DIM (Figure 5a), whereas multiparous metritis cows had lesser $(P \leq 0.05)$ blood glucose concentrations than multiparous SCE cows or healthy multiparous cows at 28 and 42 DIM (Figure 5b). There was also a main effect of parity $(P<0.001)$ and time $(P<0.001)$. Overall, primiparous cows had greater $(P<0.001)$ blood glucose concentration than multiparous cows $(3.89 \pm$ 0.05 vs. $3.51 \pm 0.04 \mathrm{mmol} / \mathrm{L})$. The effect of time $(P$ $<0.001$ ) showed that blood glucose concentrations decreased sharply from the day of calving to its lowest value at 7 DIM and recovered from 7 to 42 DIM; however, blood glucose at 42 DIM was still lower than on the day of calving. No other variable affected blood glucose concentrations. Simple linear regression showed
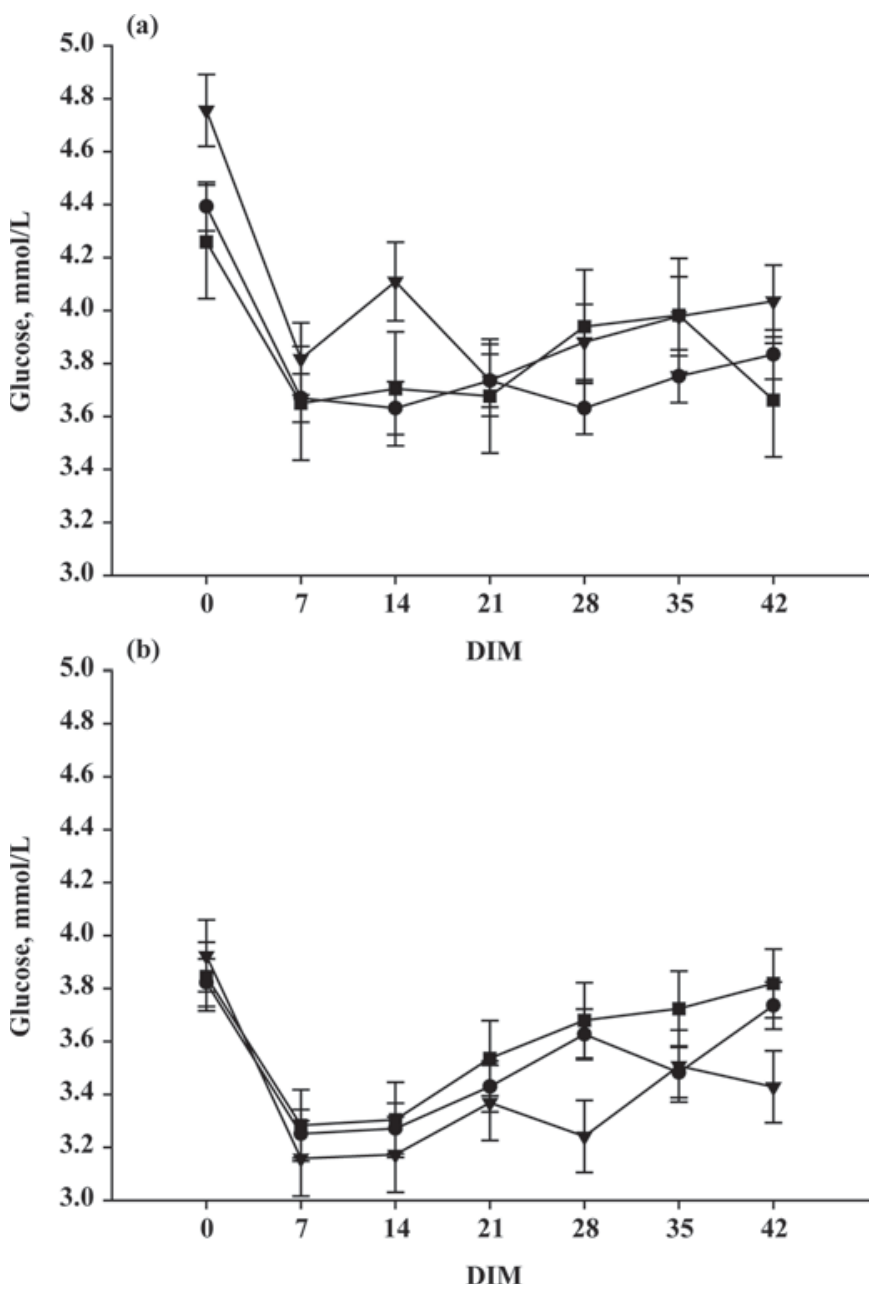

Figure 5. Least squares means \pm SEM for blood glucose concentrations for a) primiparous cows and b) multiparous cows that developed metritis up to 14 DIM ( $\boldsymbol{\nabla})$, had subclinical endometritis at 42 $\operatorname{DIM}(\mathbf{\square})$, or remained healthy up to $42 \operatorname{DIM}(\bullet)$.

that PMN glycogen concentration was positively associated with plasma glucose concentration (glycogen $=$ $-4.06+6.74 \times$ glucose; $P<0.001$ ); however, glucose explained only $5 \%\left(\mathrm{R}^{2}=0.05\right)$ of the variation in PMN glycogen concentration.

Figure 6 shows the plasma cortisol concentrations from calving until 21 DIM according to disease status. There was an interaction between uterine disease and time $(P=0.14)$ on plasma cortisol concentrations, which showed that metritis cows had greater $(P=$ 0.04) plasma concentration of cortisol than SCE cows at calving and had lower $(P=0.03)$ cortisol concentration than healthy cows at 14 DIM. There was also a tendency for an effect of parity $(P=0.06)$ in which primiparous cows had higher plasma cortisol concentration than multiparous cows $(25.4 \pm 2.4$ vs. $20.3 \pm 1.5$ $\mathrm{nmol} / \mathrm{L})$. Simple linear regression showed that plasma 


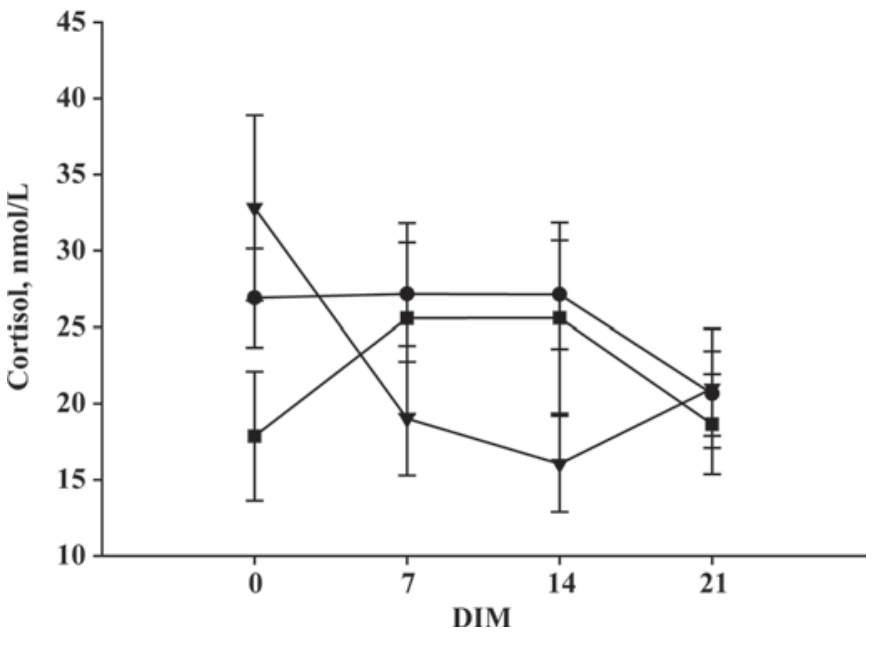

Figure 6. Least squares means \pm SEM for plasma cortisol concentrations for cows that developed metritis up to 14 DIM ( $\boldsymbol{\nabla})$, had subclinical endometritis at 42 DIM $(\boldsymbol{\square})$, or remained healthy up to 42 $\operatorname{DIM}(\bullet)$.

glucose was positively associated with plasma cortisol (glucose $=3.45+0.0074 \times$ cortisol $P<0.001 ; \mathrm{R}^{2}=$ $0.06)$; however, plasma cortisol concentration explained only $6 \%$ of the variation in plasma glucose concentration.

Figure 7 shows the weekly average for the daily milk yield for primiparous (Figure 7a) and multiparous (Figure $7 \mathrm{~b}$ ) cows from the week of calving (0-7 DIM) until the sixth week after calving (36- 42 DIM), according to disease status. There was a 3 -way interaction among uterine disease, parity, and time $(P<0.001)$ on milk yield concentrations. Primiparous metritis cows had decreased $(P<0.10)$ average daily milk yield compared with primiparous SCE cows from the second (8-14 DIM) until the fourth (22-28 DIM) week of lactation and decreased $(P<0.10)$ milk yield compared with healthy primiparous cows on the third (15-21 DIM) and fourth (22-28 DIM) weeks of lactation. Milk yield did not differ $(P>0.20)$ between SCE and healthy primiparous cows at any time point. Weekly average milk yield was greater $(P \leq 0.05)$ for multiparous metritis cows than for multiparous SCE cows and healthy multiparous cows on the fifth (29-35 DIM) and sixth (36-42 DIM) weeks of lactation. Healthy multiparous cows also had greater $(P \leq 0.05)$ milk yield than multiparous SCE cows on the fifth and sixth weeks of lactation (Figure $7 \mathrm{~b}$ ). There was also a main effect of parity $(P<0.001)$ and time $(P<0.001)$. Overall, primiparous cows had lesser $(P<$ $0.001)$ milk yield than multiparous cows $(29.2 \pm 0.9$ vs. $39.0 \pm 0.8 \mathrm{~kg} / \mathrm{d})$. The effect of time $(P<0.001)$ showed that milk yield increased sharply from the first 7 DIM until 28 DIM and then reached a plateau until 42 DIM. Simple linear regression showed that plasma glucose

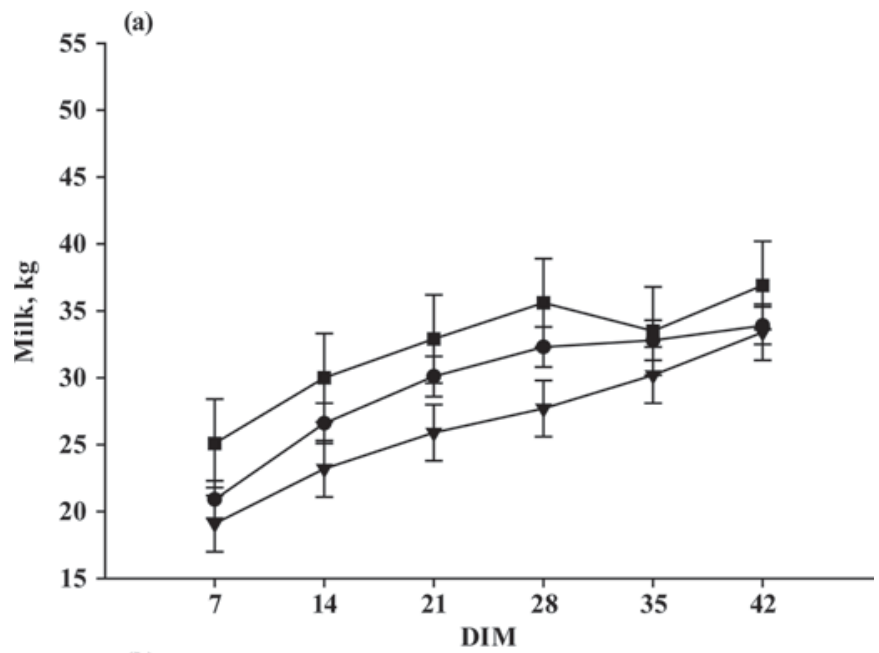

(b)

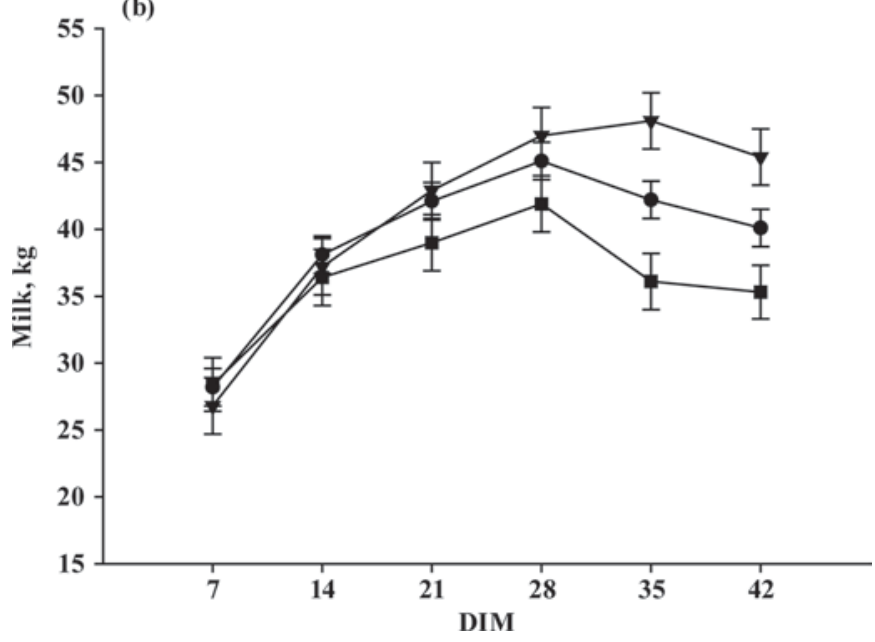

Figure 7. Least squares means \pm SEM for weekly milk yield for a) primiparous cows and b) multiparous cows that developed metritis up to 14 DIM ( $)$, had subclinical endometritis at 42 DIM ( $)$, or remained healthy up to 42 DIM $(\bullet)$. Milk yields are the daily average for the week, starting at calving.

was negatively associated with milk yield (glucose $=$ $4.03-0.0125 \times$ milk; $\left.P<0.001 ; \mathrm{R}^{2}=0.08\right)$; however, milk yield explained only $8 \%$ of the variation in plasma glucose concentration.

Figure 8 shows the plasma insulin concentrations for primiparous (Figure 8a) and multiparous (Figure 8b) cows according to disease status up to 42 DIM. There was a 3-way interaction among uterine disease, parity, and time $(P=0.02)$, which revealed that plasma insulin was lower for primiparous SCE cows compared with primiparous metritis cows $(27.2 \pm 8.3$ vs. 66.0 $\pm 13.1 \mathrm{pmol} / \mathrm{L} ; P=0.01)$ at $42 \mathrm{DIM}$. There was also a main effect of time $(P<0.001)$ on plasma insulin concentrations. Plasma insulin concentrations were high on the day of calving, decreased to their lowest levels at 7 DIM, and increased from 7 DIM to the 

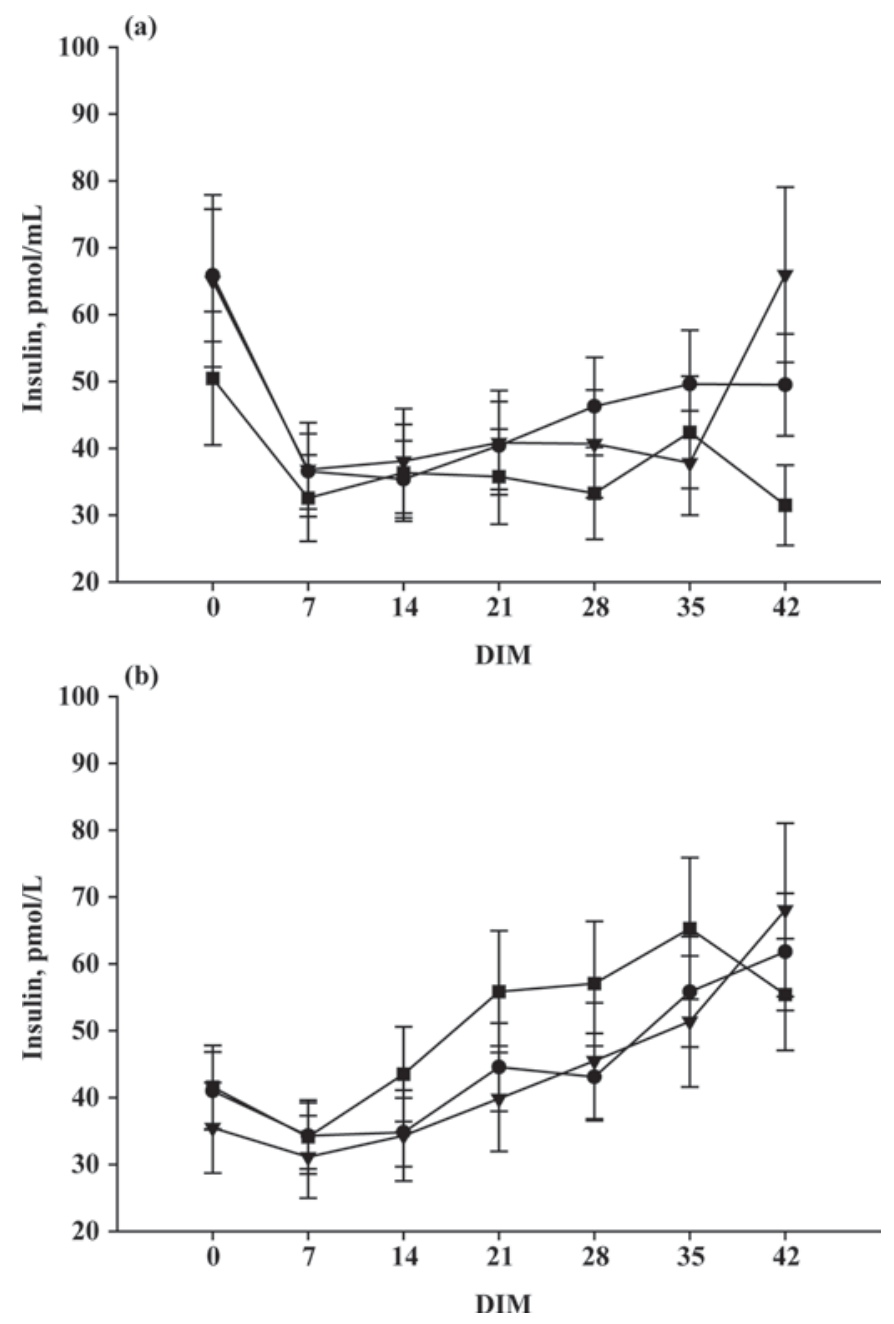

Figure 8. Least squares means \pm SEM for plasma insulin concentrations for a) primiparous cows and b) multiparous cows that developed metritis up to 14 DIM ( $\boldsymbol{\nabla})$, had subclinical endometritis at 42 DIM (ם), or remained healthy up to 42 DIM $(\bullet)$.

levels at calving by 42 DIM. The decrease in insulin concentrations between $\mathrm{d} 0$ and 7 was more accentuated for primiparous cows than for multiparous cows. However, after d 7, concentrations remained relatively constant for primiparous cows, whereas there was a steady increase in concentration for multiparous cows. Furthermore, multiparous cows with metritis had the lowest concentrations of insulin throughout, whereas the same was true for primiparous cows with SCE. No other variable affected plasma insulin concentrations. Simple linear regression showed that plasma insulin concentration was positively associated with plasma glucose concentration (insulin $=-19.72+19.93 \times$ glucose; $\left.P<0.001 ; \mathrm{R}^{2}=0.08\right)$; however, plasma glucose explained only $8 \%$ of the variation in plasma insulin concentration. There was no effect of uterine disease $(P$ $=0.67)$ or interaction between uterine disease and time
$(P=0.27)$ on glucose:insulin ratio. There was an effect of time $(P=0.01)$, which showed that glucose:insulin ratio was greater $(P<0.05)$ at 7 and 14 DIM than at the other time points.

Figure 9 shows the plasma glucagon concentrations according to disease status up to 42 DIM. The SCE cows had an overall greater $(P=0.04)$ plasma glucagon concentration than healthy cows and tended to have greater $(P=0.06)$ plasma glucagon than metritis cows. Plasma glucagon concentrations were similar $(P=0.96)$ among metritis cows and healthy cows. There was an interaction with time $(P=0.003)$, which revealed that most of the differences were on the day of calving and at 7,28 , and 35 DIM. There was also a main effect of parity $(P<0.001)$ and time $(P<0.001)$ on plasma glucagon concentrations. Multiparous cows had greater glucagon concentration than primiparous cows (109.3 \pm 3.4 vs. $91.7 \pm 4.0 \mathrm{pg} / \mathrm{mL}$ ). Plasma glucagon concentrations were lowest on the day of calving, increased from calving until 28 DIM, and then decreased slightly until 42 DIM. No other variable affected plasma glucagon concentrations. Simple linear regression showed that plasma glucagon concentration was negatively associated with plasma glucose concentration (glucagon $=$ $156.3-15.38 \times$ glucose; $\left.P<0.001 ; \mathrm{R}^{2}=0.08\right)$; however, plasma glucose explained only $8 \%$ of the variation in plasma glucagon concentration.

Plasma estradiol concentration on the day of calving was associated $(P=0.08)$ with uterine disease. Metritis cows had greater $(P=0.02)$ plasma estradiol concentration than healthy cows (median $=29.7$ vs. $1.9 \mathrm{pmol} / \mathrm{L}$ ); however, concentration in both groups was similar $(P>$ 0.38 ) to $\mathrm{SCE}$ cows $($ median $=24.0 \mathrm{pmol} / \mathrm{L})$.

\section{DISCUSSION}

This study aimed to elucidate the link between negative energy balance and immunosuppression, which seems to be at the root of the problem of increased risk of infectious diseases around parturition (Goff and Horst, 1997). Therefore, we investigated cellular and metabolic parameters that could account for the decrease in PMN function in high-producing dairy cows and, more specifically, cows that develop uterine disease. Whereas metritis is an acute process caused by bacterial contamination around calving and is characterized by fetid uterine discharge and fever (Bondurant, 1999; Sheldon and Dobson, 2004), SCE can be considered a chronic condition in which cows fail to clear bacterial contaminants completely (Gilbert et al., 2007). To evaluate the response to inflammation and to support our clinical diagnosis of metritis (Smith et al., 1998; Huzzey et al., 2009), we evaluated the acute phase protein haptoglobin. As reported previously, cows that developed 
metritis, which is an acute and more severe process, had increased haptoglobin levels around the time of metritis diagnosis (Skinner et al., 1991). Although SCE is usually diagnosed after 35 DIM (Gilbert et al., 2005), the slight increase in haptoglobin concentration at 7 DIM in cows that were later diagnosed with SCE indicates that a mild inflammatory process may be taking place early in lactation; however, haptoglobin concentrations were still similar to those of control cows, which agrees with Skinner et al. (1991).

Multiparous cows that developed metritis or SCE had decreased DMI and greater NEFA and BHBA plasma concentrations (Hammon et al., 2006). Our findings confirmed that cows that develop uterine disease experience a greater degree of negative energy balance in the first 2 wk of lactation. Nonetheless, our data contrasts with the results in the study by Hammon et al. (2006) where the differences persisted until the fourth week of lactation. Hammon et al. (2006) also observed that DMI was affected in cows that developed uterine disease until the fifth week of lactation; it is possible that, in our study, DMI for cows that developed uterine disease was not so severely affected. Also, dextrose treatment of cows diagnosed with ketosis could have narrowed the differences between cows that developed metritis and healthy cows.

High-producing dairy cows (Kehrli et al., 1989; Gilbert et al., 1993; Goff and Horst, 1997; Mallard et al., 1998) and especially cows that develop uterine disease (Cai et al., 1994; Kim et al., 2005; Hammon et al., 2006) experience a reduction in neutrophil function such as chemotaxis, phagocytosis, and killing ability around calving. Several factors could account for the loss in PMN function, such as increases in blood estradiol and cortisol concentrations around calving or deficit in nutrients and minerals such as vitamins A and E, calcium, and selenium (Goff and Horst, 1997; Kimura et al., 2006; Rutigliano et al., 2008). For this work, we focused on the immediate source of energy for PMN function such as glucose, especially its storage form glycogen (Weisdorf et al., 1982a; Kim et al., 2006). We also evaluated hormones such as estradiol, cortisol, insulin, and glucagon that could affect PMN function, or are involved in glucose homeostasis, or both. We observed that PMN glycogen concentration was greatly reduced in all cows from the first to the third week after calving, which could help to explain the overall decrease in PMN function. Importantly, cows that developed uterine disease had decreased PMN glycogen levels around calving and later in lactation, which could compromise PMN response to bacterial contamination. Most cows are infected around calving (Sheldon and Dobson, 2004); therefore, prompt and effective PMN response after infection is critical for bacterial clear-

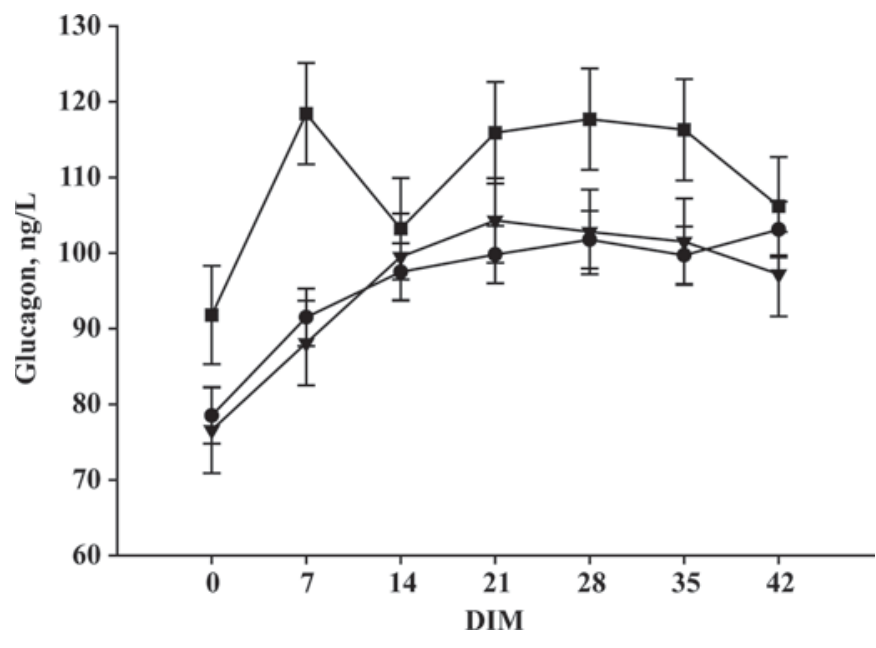

Figure 9. Least squares means \pm SEM for plasma glucagon concentrations for cows that developed metritis up to 14 DIM ( $\nabla)$, had subclinical endometritis at 42 DIM (ם), or remained healthy up to 42 $\operatorname{DIM}(\mathbf{0})$.

ance and prevention of disease. In fact, data from our laboratory indicate that cows with the greatest influx of PMN to the uterus on the day of calving have the lowest rates of positive bacterial culture and prevalence of SCE later on (Gilbert et al., 2007). Blood glucose concentration was positively associated with PMN glycogen concentration; therefore, it seems plausible that glucose deficiency could lead to a decrease in PMN glycogen. It is important to note that circulating glucose concentration starts to decrease before calving (Vazquez-Añon et al., 1994); therefore, intracellular glycogen reserves in neutrophils may be more reflective of prepartum glucose concentration than contemporary glucose status. Blood glucose concentration at calving was greater in cows that developed metritis, mainly because of greater levels around calving in primiparous cows. Nevertheless, low blood glucose concentration preceded low PMN glycogen concentration in all groups during the study; therefore, lower PMN glycogen on the day of calving could have been caused by lower glucose before calving (Vazquez-Añon et al., 1994). Greater glucose levels around calving could have been caused by an increase in cortisol levels, which would induce gluconeogenesis in the liver. Furthermore, exposure to high levels of cortisol could exacerbate the state of immunosuppression (Roth and Kaeberle, 1982). Indeed, we did observe greater cortisol levels at calving in cows that developed metritis compared with cows that had SCE; however, concentrations were not different from healthy cows. Cortisol levels were decreased at 14 DIM for cows that developed metritis compared with healthy cows, which might be a consequence of the disease because metritis occurred before 14 DIM. Greater corti- 
sol concentrations in primiparous cows were expected because these cows experience stressful events such as frequent pen moves, more interactions with the herd personnel, calving itself, and milking for the first time. Greater cortisol concentrations in primiparous cows could contribute to the overall higher metritis incidence observed in primiparous cows (Goshen and Shpigel, 2006). Although glucose is an important energy source for leukocytes (Weisdorf et al., 1982a,b; Ohtsuka et al., 2006), acute hyperglycemia, as is observed around calving, impairs leukocyte function and increases the risk for infection (Blondet and Beilman, 2007). Therefore, whereas low glucose shortly after calving might impair the ability of PMN to maintain intracellular glycogen and affect PMN function, high glucose at calving might also be detrimental.

Whereas cortisol is the main determinant of blood glucose levels at calving, glucose utilization for milk synthesis is the main factor affecting blood glucose concentrations shortly after calving (Vazquez-Añon et al., 1994; Bell, 1995; Guo et al., 2008). Indeed, milk yield was negatively associated with blood glucose concentration. Milk yield according to disease status followed a pattern opposite that for blood glucose concentration and may help to explain some of the differences observed in glucose levels. Also, as observed for blood glucose concentration, there were major differences in milk yield according to disease status between primiparous and multiparous cows. Milk yield is usually decreased for primiparous and multiparous cows that develop metritis (Rajala and Gröhn, 1998; Goshen and Shpigel, 2006; Huzzey et al., 2007); however, some studies have reported no difference (Fourichon et al., 1999). Herein we observed decreased milk yield for primiparous metritis cows, whereas multiparous metritis cows actually had increased milk yields. It is possible that increased genetic merit for milk production in multiparous cows that developed metritis accounted for the differences observed; however, this could be specific to the sample of the population used in our experiment and needs to be further investigated. Milk yields for cows that develop SCE have not been reported previously. Whereas no difference was observed between SCE and healthy primiparous cows, SCE multiparous cows produced less milk than metritis and healthy multiparous cows. It is possible that other factors that affect milk yield, such as subclinical mastitis, ruminal acidosis, or lameness could be associated with SCE; therefore, further experiments need to be conducted to confirm our findings.

During late gestation and early lactation, there is establishment of insulin resistance in peripheral tissues (Bell and Bauman, 1997), which is caused by an increase in growth hormone (Bell and Bauman, 1997) and NEFA concentrations in the blood (Pires et al.,
2007). Therefore, greater NEFA concentrations in cows that developed uterine disease and in primiparous cows in general could have induced insulin resistance and accounted for the observed differences in glucose levels. Nonetheless, glucose:insulin ratio, an indicator of insulin resistance, was not associated with uterine disease. Expectedly, glucose:insulin ratio was increased shortly after calving, indicating establishment of insulin resistance in all cows in early lactation. Insulin followed a pattern very close to the glucose pattern. The only difference observed was lower plasma insulin concentration at 42 DIM for cows that had SCE. Accordingly, those cows also had decreased concentration of glucose at that time.

In combination with insulin, glucagon is responsible for glucose homeostasis and can affect neutrophil function (Petersen et al., 1978; Deitch and Bridges, 1987; Al-essa et al., 1993). Because of its role in promoting gluconeogenesis to maintain normoglycemia, plasma glucagon concentration was negatively associated with blood glucose concentration; as glucose decreased, glucagon increased. Therefore, greater glucagon levels in multiparous cows were a consequence of lesser glucose in those cows. Cows that had SCE had greater glucagon concentration than healthy cows or cows that developed metritis. Glucagon acts by binding to its receptor on PMN and activating phosphorylase A, which promotes glycogenolysis (Petersen et al., 1978; Al-essa et al., 1993). Glucagon impairs PMN chemotactic and bactericidal activity (Deitch and Bridges, 1987), which could be a predisposing factor for the development of SCE.

Last, plasma estradiol on the day of calving is also thought to contribute to the overall immunosuppression observed in dairy cows around calving (Goff and Horst, 1997; Wyle and Kent, 1977); indeed, we observed higher estradiol concentrations on the day of calving for cows that developed uterine disease. Nonetheless, only plasma estradiol concentrations for cows that developed metritis were different from healthy controls. Plasma estradiol peaks right before calving and decreases quickly after calving (Radcliff et al., 2003), but we were still able to detect significant differences in cows that developed metritis. Therefore, estradiol might be involved in immunosuppression in cows that develop uterine disease and deserves further investigation. Although all samples were taken on the day of calving, the actual interval from calving varied, which could influence our results. These results should be interpreted with caution and viewed as preliminary.

Intuitively, metabolic parameters for cows with SCE might be expected to be intermediate between those for cows with metritis and healthy cows. This was not our observation in this study, suggesting that SCE is not 
simply a milder form of uterine disease than puerperal metritis (or clinical endometritis), but rather has a distinct pathogenesis differing in its nature or its timing from other forms of postpartum uterine disease.

\section{CONCLUSIONS}

We confirmed that cows that develop uterine disease experience a greater degree of negative energy balance as indicated by greater levels of NEFA and BHBA around calving. All cows experienced a decrease in PMN glycogen concentration in the first 3 wk after calving, which could account for the overall immunosuppression observed at this time. Furthermore, cows that developed uterine disease underwent a greater depression of PMN glycogen concentration than cows that remained healthy. At this point it is not clear why cows that developed uterine disease had diminished PMN glycogen stores, but it seems that blood glucose is involved. Glucose was mainly related to cortisol levels around calving and to milk yields later on. Greater cortisol levels in primiparous cows could contribute to their greater incidence of metritis; therefore, strategies to decrease stress around calving may have the potential to decrease the incidence of metritis in this group. We were not able to find any association between uterine disease and plasma insulin. Glucagon, on the other hand, was increased in cows that developed SCE, which could impair their leukocyte function and predispose these cows to SCE. Greater plasma estradiol levels at calving in cows that developed metritis could be another contributing factor to their immunosuppression. Cows that developed metritis or SCE had several metabolic and hormonal changes that could account for their exacerbated immunosuppression, including greater degree of negative energy balance, failure to maintain neutrophil glycogen concentration, alteration in glucose homeostasis around calving, and increased concentrations of estradiol, cortisol, and glucagon.

\section{ACKNOWLEDGMENTS}

This project was supported in part by Pfizer Animal Health Inc. (New York, NY) and in part by the Cornell University Agricultural Experiment Station federal formula funds, project no. NYC-480864, received from Cooperative State Research, Education, and Extension Service, USDA. Any opinions, findings, conclusions, or recommendations expressed in this publication are those of the authors and do not necessarily reflect the view of the USDA. The authors thank Neil Rejman and the staff of Sunnyside Farms for allowing the use of their cows and facilities for this study.

\section{REFERENCES}

Al-essa, L., M. Niwa, M. Kobayashi, M. Nozaki, and K. Tsurumi. 1993. Glucagon modulates superoxide generation in human polymorphonuclear leucocytes. Life Sci. 53:1439-1445.

Bell, A. W. 1995. Regulation of organic nutrient metabolism during transition from late pregnancy to early lactation. J. Anim. Sci. 73:2804-2819.

Bell, A. W., and D. E. Bauman. 1997. Adaptations of glucose metabolism during pregnancy and lactation. J. Mammary Gland Biol. Neoplasia 2:265-278.

Bland, J. M., and D. G. Altman. 1986. Statistical methods for assessing agreement between two methods of clinical measurement. Lancet $1: 307-310$

Blondet, J. J., and G. J. Beilman. 2007. Glycemic control and prevention of perioperative infection. Curr. Opin. Crit. Care 13:421-427.

Bondurant, R. H. 1999. Inflammation in the bovine female reproductive tract. J. Anim. Sci. 77(Suppl. 2):101-110.

Borregaard, N., and T. Herlin. 1982. Energy metabolism of human neutrophils during phagocytosis. J. Clin. Invest. 70:550-557.

Butler, W. R., R. W. Everett, and C. E. Coppock. 1981. The relationships between energy balance, milk production, and ovulation in postpartum Holstein cows. J. Anim. Sci. 53:742748.

Cai, T. Q., P. G. Weston, L. A. Lund, B. Brodie, D. J. McKenna, and W. C. Wagner. 1994. Association between neutrophil functions and periparturient disorders in cows. Am. J. Vet. Res. 55:934-943.

Cheong, S. H., D. V. Nydam, K. N. Galvao, and R. O. Gilbert. 2008. Prevalence of subclinical endometritis in lactating New York State dairy cows shortly before first service. Hung. Vet. J. 130(Suppl. II):156. (Abstr.)

Deitch, E. A., and R. M. Bridges. 1987. Stress hormones modulate neutrophil and lymphocyte activity in vitro. J. Trauma 27:11461154.

Doepel, L., H. Lapierre, and J. J. Kennelly. 2002. Peripartum performance and metabolism of dairy cows in response to prepartum energy and protein intake. J. Dairy Sci. 85:2315-2334.

Ehrhardt, R. A., R. M. Slepetis, A. W. Bell, and Y. R. Boisclair. 2001. Maternal leptin is elevated during pregnancy in sheep. Domest. Anim. Endocrinol. 21:85-96.

Ferguson, J. D., D. T. Galligan, and N. Thomsen. 1994. Principal descriptors of body condition score in Holstein cows. J. Dairy Sci. 77:2695-2703.

Fourichon, C., H. Seegers, N. Bareille, and F. Beaudeau. 1999. Effects of disease on milk production in the dairy cow: A review. Prev. Vet. Med. 41:1-35.

Gilbert, R. O., Y. T. Gröhn, P. M. Miller, and D. J. Hoffman. 1993. Effect of parity on periparturient neutrophil function in dairy cows. Vet. Immunol. Immunopathol. 36:75-82.

Gilbert, R. O., N. R. Santos, K. N. Galvão, S. B. Brittin, and H. B. Roman. 2007. The relationship between postpartum uterine bacterial infection (BI) and subclinical endometritis (SE). J. Dairy Sci. 90(Suppl. 1):469. (Abstr.)

Gilbert, R. O., S. T. Shin, C. L. Guard, H. N. Erb, and M. Frajblat. 2005. Prevalence of endometritis and its effects on reproductive performance of dairy cows. Theriogenology 64:1879-1888.

Goff, J. P., and R. L. Horst. 1997. Physiological changes at parturition and their relationship to metabolic disorders. J. Dairy Sci. 80:1260-1268.

Goshen, T., and N. Y. Shpigel. 2006. Evaluation of intrauterine antibiotic treatment of clinical metritis and retained fetal membranes in dairy cows. Theriogenology 66:2210-2218.

Guo, J., R. R. Peters, and R. A. Kohn. 2008. Evaluation of a mechanistic model of glucose and lipid metabolism in periparturient cows. J. Dairy Sci. 91:4293-4300.

Hammon, D. S., I. M. Evjen, T. R. Dhiman, J. P. Goff, and J. L. Walters. 2006. Neutrophil function and energy status in Holstein cows with uterine health disorders. Vet. Immunol. Immunopathol. 113:21-29.

Hussain, A. M. 1989. Bovine uterine defense mechanism: A review. J. Vet. Med. B. 36:641-651. 
Huzzey, J. M., T. F. Duffield, S. J. LeBlanc, D. M. Veira, D. M. Weary, and M. A. von Keyserlingk. 2009. Short communication: Haptoglobin as an early indicator of metritis. J. Dairy Sci. 92:621-625.

Huzzey, J. M., D. M. Veira, D. M. Weary, and M. A. G. von Keyserlingk. 2007. Prepartum behavior and dry matter intake indentify dairy cows at risk for metritis. J. Dairy Sci. 90:3220-3233.

Kehrli, M. E. Jr., and J. P. Goff. 1989. Periparturient hypocalcemia in cows: Effects on peripheral blood neutrophil and lymphocyte function. J. Dairy Sci. 72:1188-1196.

Kehrli, M. E. Jr., B. J. Nonnecke, and J. A. Roth. 1989. Alterations in bovine neutrophil function during the periparturient period. Am. J. Vet. Res. 50:207-214.

Keppler, D., and K. Decker. 1974. Glycogen. Determination with amyloglucosidase. Pages 1127-1131 in Methods of Enzymatic Analysis. H. U. Bergmeyer, ed. Academic, New York, NY.

Kim, I. H., K. J. Na, and M. P. Yang. 2005. Immune responses during the peripartum period in dairy cows with postpartum endometritis. J. Reprod. Dev. 51:757-764.

Kim, S. Y., A. D. Nguyen, J. L. Gao, P. M. Murphy, B. C. Mansfield, and J. Y. Chou. 2006. Bone marrow-derived cells require a functional glucose 6-phosphate transporter for normal myeloid functions. J. Biol. Chem. 281:28794-28801.

Kimura, K., T. A. Reinhardt, and J. P. Goff. 2006. Parturition and hypocalcemia blunts calcium signals in immune cells of dairy cattle. J. Dairy Sci. 89:2588-2595.

Kuehl, F. A. Jr., and R. W. Egan. 1980. Prostaglandins, arachidonic acid, and inflammation. Science 210:978-984.

Mallard, B. A., J. C. Dekkers, M. J. Ireland, K. E. Leslie, S. Sharif, C. L. Vankampen, L. Wagter, and B. N. Wilkie. 1998. Alteration in immune responsiveness during the peripartum period and its ramification on dairy cow and calf health. J. Dairy Sci. 81:585595.

McCutcheon, S. N., and D. E. Bauman. 1986. Effect of chronic growth hormone treatment on responses to epinephrine and thyrotropinreleasing hormone in lactating cows. J. Dairy Sci. 69:44-51.

NRC. 2001. Nutrient Requirements of Dairy Cattle. 7th rev. ed. Natl. Acad. Sci., Washington, DC.

Ohtsuka, H., C. Watanabe, M. Kohiruimaki, T. Ando, D. Watanabe, M. Masui, T. Hayashi, R. Abe, M. Koiwa, S. Sato, and S. Kawamura. 2006. Comparison of two different nutritive conditions against the changes in peripheral blood mononuclear cells of periparturient dairy cows. J. Vet. Med. Sci. 68:1161-1166.

Petersen, C. S., T. Herlin, and V. Esmann. 1978. Effects of catecholamines and glucagon on glycogen metabolism in human polymorphonuclear leukocytes. Biochim. Biophys. Acta 542:7787.

Pires, J. A., A. H. Souza, and R. R. Grummer. 2007. Induction of hyperlipidemia by intravenous infusion of tallow emulsion causes insulin resistance in Holstein cows. J. Dairy Sci. 90:2735-2744.
Radcliff, R. P., B. L. McCormack, B. A. Crooker, and M. C. Lucy. 2003. Plasma hormones and expression of growth hormone receptor and insulin-like growth factor-I mRNA in hepatic tissue of periparturient dairy cows. J. Dairy Sci. 86:3920-3926.

Rajala, P. J., and Y. T. Gröhn. 1998. Effects of dystocia, retained placenta, and metritis on milk yield in diary cows. J. Dairy Sci. 81:3172-3181.

Roth, J. A., and M. L. Kaeberle. 1981. Evaluation of bovine polymorphonuclear leukocyte function. Vet. Immunol. Immunopathol. 2:157-174.

Roth, J. A., and M. L. Kaeberle. 1982. Effect of glucocorticoids on the bovine immune system. J. Am. Vet. Med. Assoc. 180:894-901.

Rutigliano, H. M., F. S. Lima, R. L. A. Cerri, L. F. Greco, J. M. Vilela, V. Magalhães, F. T. Silvestre, W. W. Thatcher, and J. E. P. Santos. 2008. Effects of method of presynchronization and source of selenium on uterine health and reproduction in dairy cows. J. Dairy Sci. 91:3323-3336.

Sechen, S. J., F. R. Dunshea, and D. E. Bauman. 1990. Somatotropin in lactating cows: Effect on response to epinephrine and insulin. Am. J. Physiol. 258:E582-E588.

Sheldon, I. M., and H. Dobson. 2004. Postpartum uterine health in cattle. Anim. Reprod. Sci. 82-83:295-306.

Sheldon, I. M., G. S. Lewis, S. LeBlanc, and R. O. Gilbert. 2006. Defining postpartum uterine disease in cattle. Theriogenology 65:1516-1530.

Skinner, J. G., R. A. Brown, and L. Roberts. 1991. Bovine haptoglobin response in clinically defined field conditions. Vet. Rec. 128:147149

Smith, B. I., G. A. Donovan, C. A. Risco, C. R. Young, and L. H. Stanker. 1998. Serum haptoglobin concentrations in Holstein dairy cattle with toxic puerperal metritis. Vet. Rec. 142:83-85.

Suriyasathaporn, W., C. Heuer, E. N. Noordhuizen-Stassen, and Y. H. Schukken. 2000. Hyperketonemia and the impairment of udder defense: A review. Vet. Res. 31:397-412.

Vazquez-Añon, M., S. Bertics, M. Luck, R. R. Grummer, and J. Pinheiro. 1994. Peripartum liver triglyceride and plasma metabolites in dairy cows. J. Dairy Sci. 77:1521-1528.

Weisdorf, D. J., P. R. Craddock, and H. S. Jacob. 1982a. Glycogenolysis versus glucose transport in human granulocytes: Differential activation in phagocytosis and chemotaxis. Blood 60:888-893.

Weisdorf, D. J., P. R. Craddock, and H. S. Jacob. 1982b. Granulocytes utilize different energy sources for movement and phagocytosis. Inflammation 6:245-256.

Wyle, F. A., and J. R. Kent. 1977. Immunosuppression by sex steroid hormones. The effect upon PHA- and PPD-stimulated lymphocytes. Clin. Exp. Immunol. 27:407-415. 